\title{
Lumbar hernia: anatomical basis and clinical aspects
}

\author{
Olivier Armstrong
}

Received: 30 October 2008 / Accepted: 31 October 2008 / Published online: 27 November 2008

(C) Springer-Verlag 2008

\section{Dear Editor,}

I read with interest the letter to the Editor written by Marios Loukas [2] and agree with most of his interesting comments.

This gives me an opportunity to insist on some points concerning lumbar hernias. They are rare and not well known and we must describe their anatomical aspects [1] which are the basis of any understanding.

First of all, if they are difficult to diagnose it is because most practitioners do not consider them, especially in obese, old patients and not traumatic events. CT Scan or MRI is very important to detect or confirm them before complication, which may occur at any time (stangulation).

Second, their classification into two types is easy: rare congenital (e.g. lumbo costo vertebral syndrome), or more often acquired in $80 \%$ of cases (post traumatic or surgery). But we must not confuse with incisional which are not true hernias but incisional ones with different physiopathology.
And finally, this discussion allows us to insist on anatomical background to know this disorder better, and this was the main aim of our paper about two spontaneous cases. The two weak points are very close and divide them in four types each may be complicated.

Superior (Grynfeldt) or inferior (Petit) spaces are easy to describe, teach and remember.

Let's hope that we read more publications on this topic: Lumbar Hernias.

\section{References}

1. Armstrong O, Hamel A, Grignon B, Ndoye JM, Hamel O, Robert R, et Rogez JM (2008) Lumbar hernia: anatomical basis and clinical aspects. Surg Radiol Anat 30:533-537

2. Loukas M, Tubs RS, Shoja M (2008) Letter to the editor Lumbar hernia: anatomical basis and clinical aspects. Surg Radiol Anat 30:609-610

O. Armstrong $(\bowtie)$

Laboratoire d'Anatomie, Faculté de Médecine,

Nantes, France

e-mail: olivier.armstrong@chu-nantes.fr 